Elizabete de Oliveira Barbosa'

O https://orcid.org/0000-0001-5812-2017

Ana Carolina de Mello Alves

Rodrigues $^{2}$

OChtps://orid.org/0000-0002-1722-1737

Vinícius Dias Rodrigues

Ohtps://orcid.org/0000-0002-6959-5992

Ester Liberato Pereira²

Ohttps://orcid.org/0000-0001-6193-9132

Luana Lemos Lean²

Ohttps://orcid.org/0000-0003-3734-6964

Alfredo Mauricio Batista de Paula² Ohttps://orid. org/0000-0002-8715-0030

Osvaldo Nascimento

Ohttps://orid.org/0000-0003-3516-485X

Renato Sobral Monteiro-Junior² Ohttps://orcid.org/0000-0002-8472-262X

\section{Move and play yourself: exergame preserves cognition of older adults as much as aerobic and strength training}

Mexa-se e jogue: exergame preserva a cognição de idosos tanto quanto o treinamento aeróbio e de força

D0I: 10.1590/0047-2085000000333

\section{MR. EDITOR,}

Simultaneous cognitive and physical stimulations can be reached by virtual reality-based exercise (exergames), which requires selective attention, decision-making, inhibitory control and cognitive flexibility'. Due to the lack of comparative studies with others training methods, this study aimed to compare the effects of exergames, strength training, and aerobic exercise on the cognitive functions of community-dwelling older adults.

This data was retrieved from a public repository ${ }^{2}$. The recruitment occurred between August 2016 and December 2019, with 19 individuals. All were in accordance with the ethical standards of the Ethical Committee of the State University of Montes Claros (1,365,041/2015). Participants were randomly allocated into three groups, featuring a quasi-experimental model: exergames (EXG), strength and balance exercises (SG), and aerobic exercise (AG).

Global cognition, short-term and working memories, semantic fluency/executive function and visuospatial attention were assessed using the Brazilian version of the Mini-Mental of State Examination (MMSE), Digit Span (DSF and DSB), animal category of verbal fluency (VF) and TrailMaking Test A (TMTA), respectively, applied before and after the intervention.

All groups performed 24 sessions, lasting 30 to 45 minutes, twice a week. EXG performed games from Nintendo Wii (Rowing Squat, In Line Lunge, Table Tilt, Sword Play Duel, Sword Play Showdown). SG performed rowing squat, anteroposterior squat, squat on the trampoline, lat pull-down, and shoulder adduction with elbow extension. AG performed a walking on a treadmill, with progressive intensity, according to the perceived subjective exertion (PSE), according $\mathrm{ACSM}^{3}$. Participants were instructed to keep the PSE between 5 and 6 points (moderate effort).

One-Way ANOVA and Kruskal-Wallis test were used with $p \leq 0.05$ significance level. The effect size values (Cohen's d) were: trivial 0-0.19, small 0.2-0.59, moderate 0.6-1.1, large 1.2-1.9, very large 2-3.9, almost perfect 4 and perfect $>4$. The same interpretation was used when the score had a negative value.

EXG, SG and AG groups were composed of 8, 6, and 5 individuals, respectively. Age, height, weight, gender and MMSE score were not different between groups $(p>0.05)$. The delta of the outcomes showed no significant difference between groups ( $p>0.05$ ). The effect size in the comparison between EXG versus SG and AG showed clinical improvement in the EXG group in most outcomes. Additionally, the effect size between EXG versus SG for MMSE, VF, DSF, DSB, and TMT A were $0.34,-0.01,0.43,-0.09$, and -1.17 , respectively, while the comparison between EXG versus AG for the same outcomes were $0.10,0.30,0.55,-0.17$, and -0.34 . The visuospatial attention was the variable with the greatest effect in favor of EXG (Online Appendix 1).

The EXG showed a moderate effect of improvement in visuospatial attention when compared to the SG. Moreover, participants from EXG showed a small effect of improvement

Received in: Mar/30/2021 Approved in: Apr/19/2021

1 Federal Fluminense University, Niterói, RJ, Brazil.

2 Montes Claros State University, Montes Claros, MG, Brazil.

Address for correspondence: Renato S. Monteiro-Junior. Avenida Rui Braga, s/n, Vila Mauriceia - 39401-089 - Montes Claros, MG, Brasil. E-mail: renato. monteiro@unimontes.br 
in global cognition and short-term memory compared to SG. Individuals from EXG exhibited a small improvement in semantic fluency/executive function, short-term memory and visuospatial attention compared to AG.

Finally, although this study had a small sample, which is a limitation, our findings showed a perspective of the applicability of exergames to maintain or improve cognitive functions of older adults as much as traditional methods of exercise.

\section{AUTHOR'S CONTRIBUTIONS}

EOB, ACMAR, VDR, ELP and OMN designed the study, collected and analyzed the data, and wrote the manuscript. AMBP and LLL wrote and reviewed the manuscript. RSMJ supervised all procedures across the work.

\section{CONFLICT OF INTERESTS}

Authors declare no conflict of interest.

\section{ACKNOWLEDGEMENT}

Coordenação de Aperfeiçoamento de Pessoal de Nível Superior - Brasil (Capes) - Finance Code 001; Conselho Nacional de Desenvolvimento Científico e Tecnológico (CNPq) and Fundação de Amparo à Pesquisa de Minas Gerais (Fapemig).

\section{REFERENCES}

1. Monteiro-Junior R, Vaghetti CO, Nascimento 0J, Laks J, Deslandes A. Exergames: neuroplastic hypothesis about cognitive improvement and biological effects on physical function of institutionalized older persons. Neural Regen Res. 2016;11(2):201.

2. Barbosa Ede0, Rodrigues AC, Rodrigues V, Pereira E, Leao L, Paula AM, et al. Comparison between exergames, aerobic exercise, and strength training for cognitive function in older adults. Figshare. Dataset. 2021. doi:10.6084/m9.figshare.13557269.v1

3 Garber CE, Blissmer B, Deschenes MR, Franklin BA, Lamonte MJ, Lee IM, et al. Quantity and Quality of Exercise for Developing and Maintaining Cardiorespiratory, Musculoskeletal, and Neuromotor Fitness in Apparently Healthy Adults. Med Sci Sport Exerc. 2011;43(7):1334-59. 